THE ANNALS OF "DUNĂREA DE JOS" UNIVERSITY OF GALATI

FASCICLE III, 2020, VOL. 43, NO. 1, ISSN 2344-4738, ISSN-L 1221-454X

ELECTROTECHNICS, ELECTRONICS, AUTOMATIC CONTROL, INFORMATICS

Article DOI: https://doi.org/10.35219/eeaci.2020.1.05

\title{
DC MOTOR LOAD ANALYSIS AT HSM FINISHING TRAIN
}

\author{
Marius-George Solomon, Marian Gaiceanu \\ "Dunărea de Jos" University of Galati, Faculty of Automation, Computer sciences, Electronics and Electrical \\ Engineering, Galati, Romania \\ solmarcen@yahoo.com,marian.gaiceanu@ugal.ro
}

\begin{abstract}
The hot rolling process uses a plant called a finishing train to achieve the final geometric dimensions of the strip. The finishing train is composed of 7 rolling stands. The reduction of the dimensions of the slab is made with the help of rolling cylinders that are driven by identical DC motors, for the 7 stands of the finishing train but with different speed and torque requirements. During the passage of the strip through the stands of the finishing train, the thickness reduction is different from first stand to the last one, but the material flow must remain constant. This also involves different speeds and forces on each stand. The automation system calculates and controls each motor attached to each stand differently. Moreover, the deformation force required in the stand is different in both value and the drive system that supplies it; for the first four stands the system is electromechanical and for the last three stands it is hydraulic. This difference is also reflected in the load of the gear motors. The main objective of the analysis, performed in this research, is to build an optimized loading model of the rolling motor drive motor. In order to achieve this goal, the analysis was performed on two levels: physical and virtual respectively. Physically, the load analysis involves comparing the parameters of the drive motor for a tensioned stand with an electromechanical system and a stand where the force is developed by a hydraulic system, analysis that is performed in the real finishing train. In the virtual plane, the analysis considers the comparison of the obtained parameters, by simulating the motors in Matlab Simulink with the real data recorded in operation for the same type of strip, thus verifying the factors that definitively influence the functional stability of the finishing train and opening paths for the functional optimization of this drive chain.
\end{abstract}

Keywords: DC Motor, Motor Parameters, Load Analysis, Optimized Loading Model

\section{AUTOMATION SYSTEM ARCHITECTURES}

The control is driven by the TRAPS algorithm (Fig. $1)$. This model is composed of three main parts: Basic models, Setup and Adaptation. TRAPS is an algorithm for calculating the setup of automation and actuators based on the mathematical model and the fundamental rolling equations, for adapting the optimal values of the rolling parameters based on the information of the field elements.
The automation system is structured on three levels of automation: 2,1,0, Fig. 2. The TRAPS algorithm interacts directly with both automation level 2 and level 1 to control the parameters that impact the final properties of the strip. The synthetic diagram in Fig. 2 shows the cascade of the setpoints of the algorithms towards the actuators at the level zero. Although only the TRAPS algorithm calculates the initial requirements based on a mathematical model, it is positioned on the same hierarchical level of automation with other $C I D, C T C$ and $D C S U$ process 
computers upstream and downstream of the finishing train with which it exchanges information both as inputs and outputs.

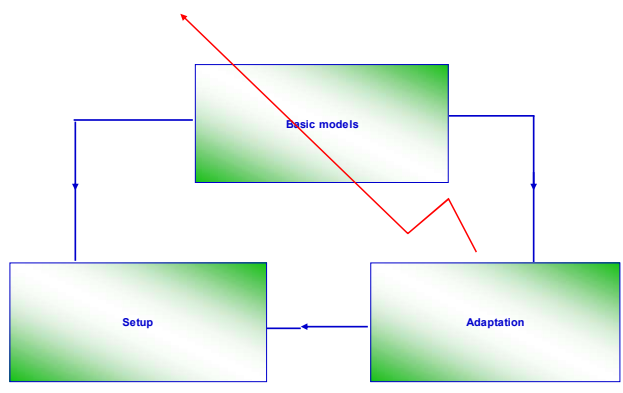

Fig. 1. TRAPS model (Source: Liberty Galati)

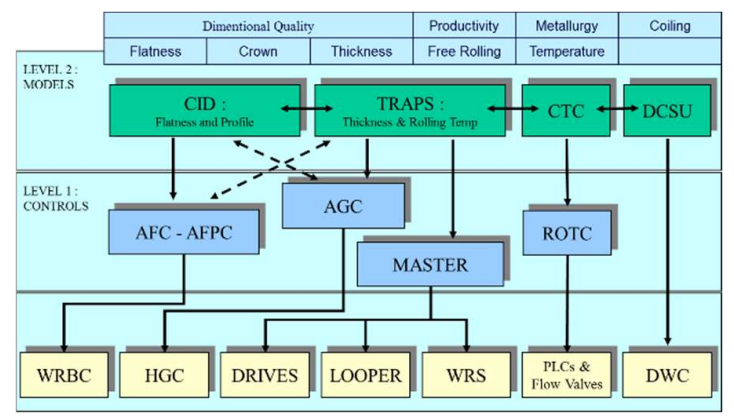

Fig. 2. Automation System (Source: Liberty Galati)

The basic functions are transmitted to the electrical or mechanical actuators on the whole finishing train as in Fig. 3, in order to ensure the setup values of the parameters. To adjust the temperature and geometric dimensions, the information taken into account is the data received from the roughing and the gauges measuring machine. Although it is an automated system, there is the possibility that each actuator can be controlled directly by the operator, over the setpoint of the automation system (Fig. 3).

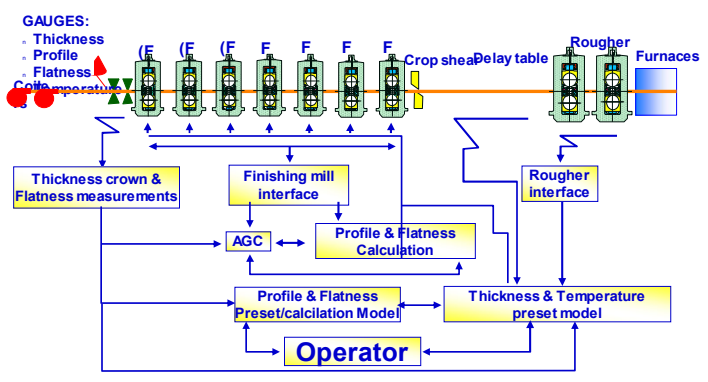

Fig. 3. Map of the Automation System (Source: Liberty Galati)

\section{ROLLING MILL, FINISHING TRAIN}

The finishing train of the hot rolling process is composed of 7 finishing stands through which the strip passes once in the direction from stand F1 to stand F7 with the speed imposed by the rolling scheme. Each box consists of two working cylinders and two support cylinders. Working cylinders are driven by a direct current motor, both at the same time by a gearbox with a torque and speed ratio of $1 / 1$. With small differences the motors are the same. The difference consists in the speed (at stand F4 it is lower) and in torque (William Roberts 1983).

The motor that is the object of this analysis is of very high power, of a special type, with 2 rotors placed on the same axis, with independent excitation (practically, 2 series motors) having the following characteristics:

Type: $2 \mathrm{P}$ 25/105-3,15, P: $2 \times 3150 \mathrm{~kW}, U_{a}: 750 \mathrm{~V}, I_{a}$ : 4490A, $U_{e x}: 70 \mathrm{~V}, I_{e x}: 279$ A, $\Omega: 97 / 270$

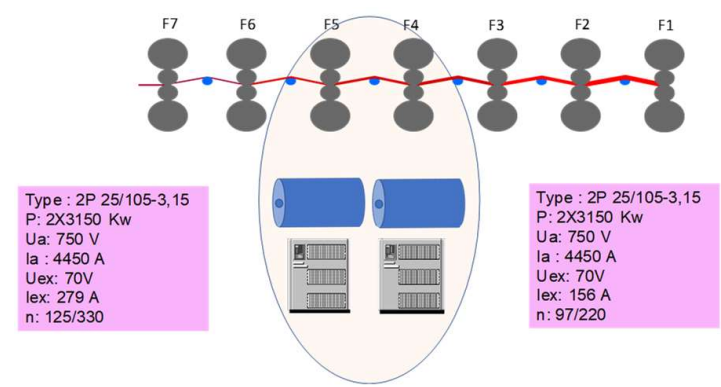

Fig. 4. Finishing train (Source: Liberty Galati)

Between the stands (Fig. 4) the material flow resulting from rolling is taken over by belt tensioners called loops. They ensure the tension of the strip between the stands and take the deformed material to keep the speed of the strip almost constant.

\section{ROLLING TORQUE}

The required torque is:

$$
\text { (1) } M=(F+\text { Fbending }) x A R C x C O F C O U
$$

$F=$ deformation force

$F_{\text {bending }}=$ bending force

$A R C$ [mm] - the length of the arc of the circle between the strip and the roller COFCOU:(1) = adaptive parameter

\section{(2) $A R C x C O F C O U=$ the level of the arm}

The torque of the motor:

$$
\text { (3) } M=K x I x \phi \_m e d
$$


$K=$ electrical parameter;

$I=$ rotor current;

$\phi \_$med $=$magnetic flux.

In order to build the $D C$ motor model (Orowan, 1943), (Fulvio Siciliano Jr., 2012) and (Hodgson, 1993 ) in the simulation environment, the catalog data of the existing motors in the plant were used and the current (torque) and speed parameters were followed. The theoretical torque was calculated using the Sims' formula (Sims, 1954).

\section{LOAD CURRENT ANALYSIS}

In the present research, the behavior of the motors at two different types of strip was analyzed, one of 4 $\mathrm{mm}$ thick and one of $10 \mathrm{~mm}$ thick. Even if they have the same alloy, the required rolling force is different. The analysis also considers the difference between the 2 motors in the stands, the difference given by the constructive particularities of the plant.

Stand F4 is provided with an electromagnetic equipment for positioning the upper cylinder box while stand F5 is equipped with hydraulic equipment.

The current analysis for determining the torque load of the motors follows the shape of the currents, the current value and the growth gradient both in the simulation environment (Gaiceanu, 2014) and in the real environment for the two motors and 2 types of strip.

\subsection{Load Current analysis for a $4 \mathrm{~mm}$ strip}

For the $4 \mathrm{~mm}$ strip, the current through the motor of the stand F4 is constant at a value of $3200 \mathrm{~A}$, zero gradient, as in Fig. 5.

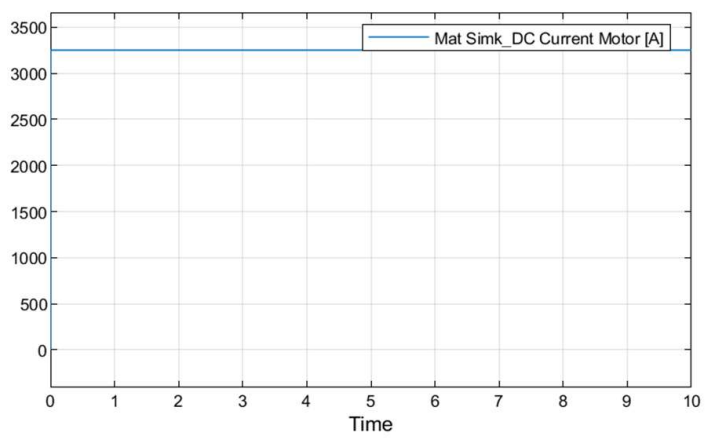

Fig. 5. Simulation results: rotor current [A]

The motor current in the plant can be assimilated as constant (with small exceptions) with a positive growth gradient between the values of $3000 \mathrm{~A}$ and 4700 A (Fig. 6).
For this type of laminated strip (4 mm), the current is within the maximum nominal limit, so that the motor load is maximum.

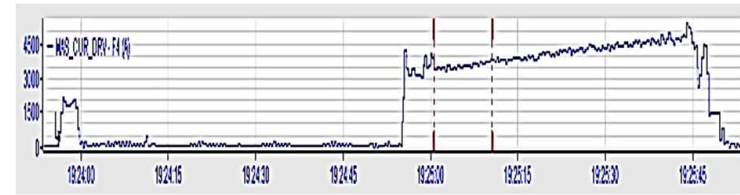

Fig. 6. Real rotor current [A] of DC motor (Source: Liberty Galati)

Usually thinner strips of up to $2 \mathrm{~mm}$ (even 1.5) are laminated so that the current reaches up to 1.7-2 the rated current. In the motor data sheet, the manufacturer specifies that the motor can be loaded up to 2.5 rated torque.

The current of F5 stand motor is lower than that of the stand F4 at a constant value of $3000 \mathrm{~A}$ in the simulated environment (Fig. 7).

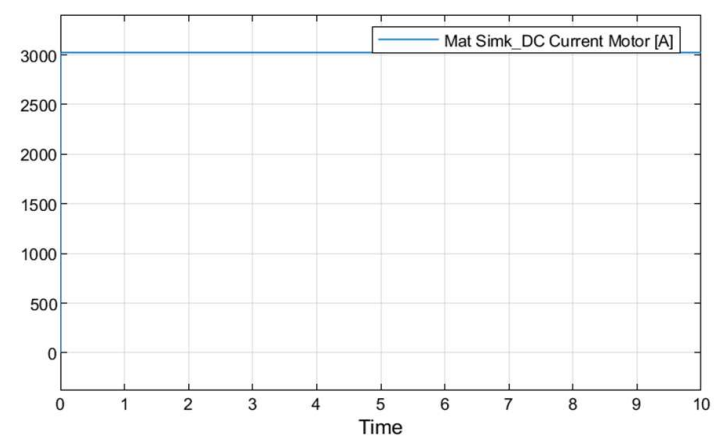

Fig. 7. Simulation results: rotor current [A]

The stand F5 is equipped with hydraulic equipment. This allows the F5 box to change its initial position during rolling (approximately $1 \mathrm{~min}$.). This leads to significant changes in current and speed during rolling. The current becomes constant after the action of the controller at a value of $3000 \mathrm{~A}$ (Fig. 8).

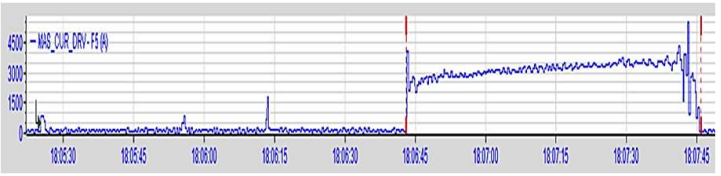

Fig. 8. Real rotor current of the DC motor (Source: Liberty Galati)

\subsection{Current analysis for a $10 \mathrm{~mm}$ strip}

Regarding the $10 \mathrm{~mm}$ strip, it is observed that the motor is almost $100 \%$ loaded but the limit is not exceeded, because the thickness jump (thickness reduction) is smaller. The action of the loops that 
take over the material flow and ensure the tension in the belt is more visible. It is seen in the large variation of the current in a small unit of time.

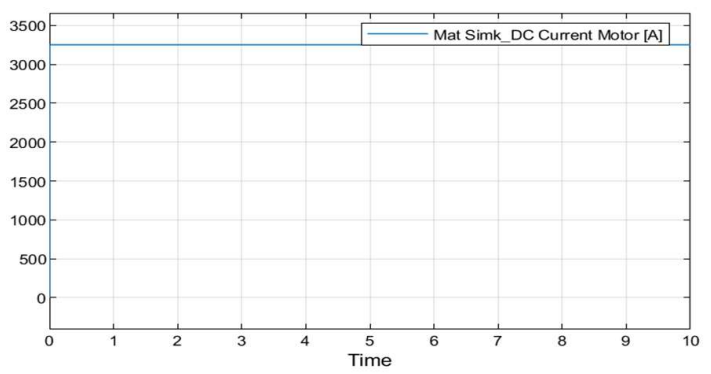

Fig. 9. Simulation results: rotor current $[\mathrm{A}]$

The value of the motor current in the simulated environment is constant with optimal load at 3200A (Fig. 9). The value of the real motor current in the plant is almost constant after a quick intervention of the controller around 3100A (Fig. 10).

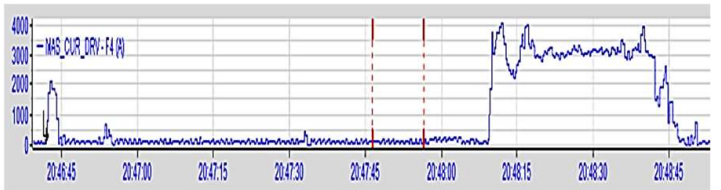

Fig. 10. Real Rotor Current of the DC Motor Source: Liberty Galati)

The stand F5 motor for the $10 \mathrm{~mm}$ strip is optimally loaded in the current, at $3000 \mathrm{~A}$ in the simulated environment (Fig. 11).

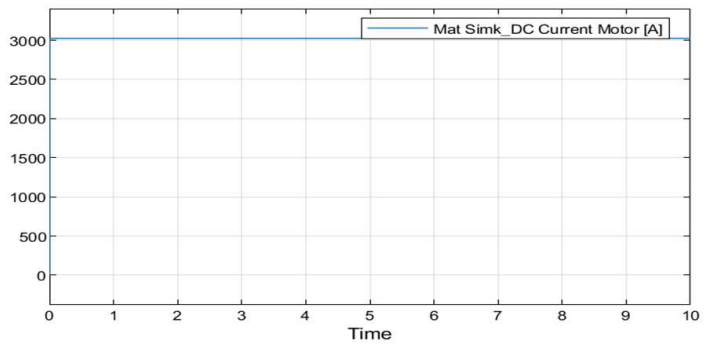

Fig. 11. Simulation results: rotor current [A]

In the real environment there are very large variations per small unit of time, variations that are given by both loops and different setpoints required by level 2 of automation which takes into account a fast reaction of the hydraulic drive and an adjustment of tension / mechanical force of the stand (Fig. 12).

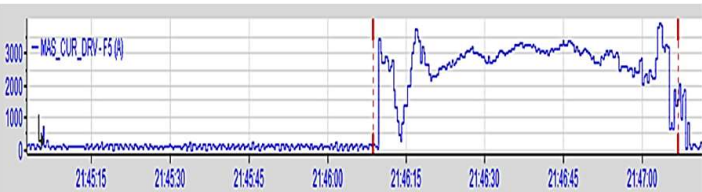

Fig. 12. Real Rotor Current of the $D C$ Motor (Source: Liberty Galati)

Although it is less charged in current and in torque implicitely, the continuous and sudden variation of the current and torque values lead in time to very high dynamic demands of the motor, demands that lead to the destruction of the rotor with on average of 4-5 years.

\section{SPEED ANALYSIS}

Another important parameter studied in this research is the motor speed. During rolling, the speed of the laminated strip must remain constant, this being achieved by adjusting the speed of the stand motors and by the action of the loops that take over the material flow following the reduction of the thickness when passing through each stand.

\subsection{Speed analysis for a $4 \mathrm{~mm}$ strip}

For the $4 \mathrm{~mm}$ strip, the motor speed is stable and the gradient increases constantly (Fig 13). The motor spins two working cylinders with $1 / 1$ reducer rate, one of the two cylinder rotating in reverse direction.

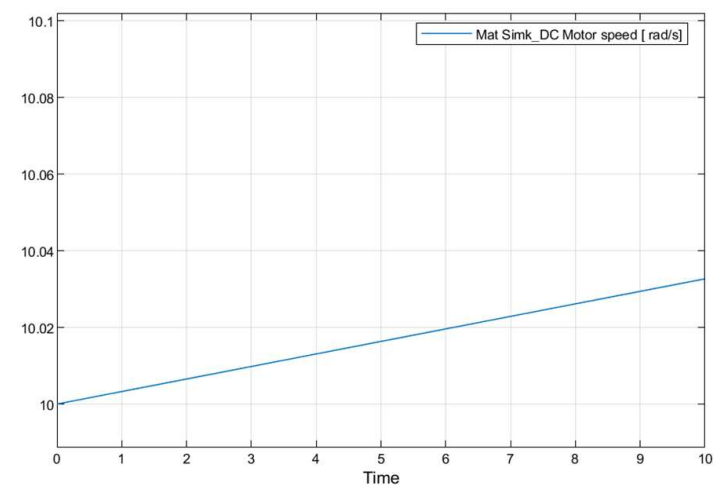

Fig. 13. Simulink results: the speed of the $D C$ motor

The speed of F4 stand motor in the plant is constant, increasing from the nominal speed of $10 \mathrm{rad} / \mathrm{s}$ to 13 $\mathrm{rad} / \mathrm{s}$ (Fig. 14). 


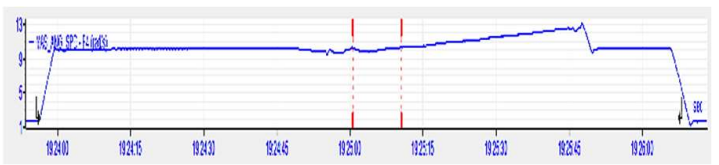

Fig. 14. Real speed of the DC Motor (Source: Liberty Galati)

The F5 stand motor has a higher speed than the F4 but also a higher growth gradient (Fig. 15).

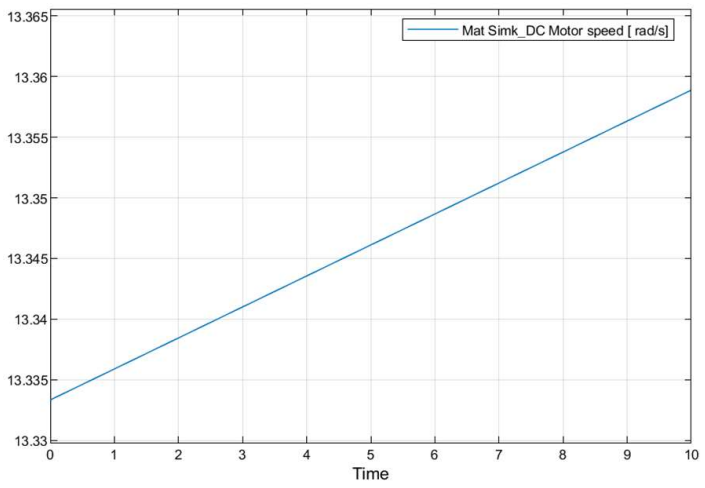

Fig. 15. Simulink results: the speed of the $D C$ motor

The motor speed in the plant is constantly increasing and falls within the limits recommended by the manufacturer. Sudden speed changes are controlled by the human operator (Fig. 16).

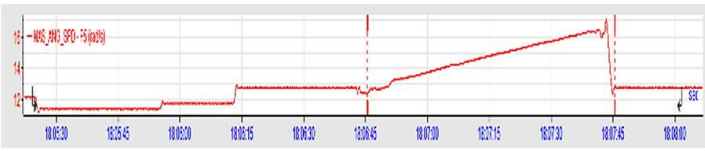

Fig. 16. Real speed of the DC Motor (Source: Liberty Galati)

\subsection{Speed analysis for a $10 \mathrm{~mm}$ strip}

The $10 \mathrm{~mm}$ strip requires a lower motor speed. The F4 stand motor in the simulated environment has a constant and increasing speed (Fig. 17).

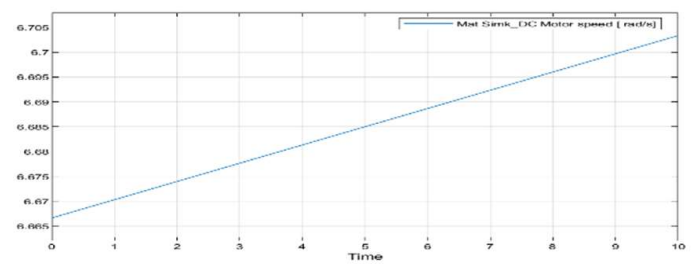

Fig. 17. Simulink result: the speed of the $D C$ motor
At the $10 \mathrm{~mm}$ strip, identical to the current analysis, the speed is not always constant, being influenced both by the strip tension modified by the loops and the human operator (Fig. 18).

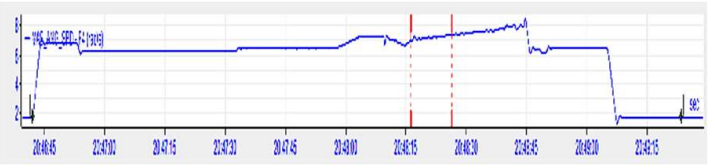

Fig. 18. Real speed of the DC Motor (Source: Liberty Galati)

In the simulated environment the motor of F5 stand has a constant and increasing speed following the same gradient as of the F4 stand (Fig. 19).

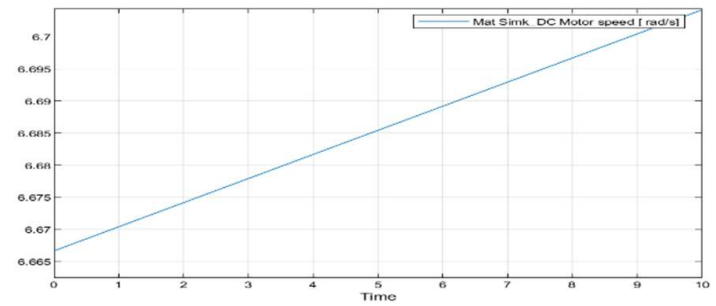

Fig. 19. Simulink result: the speed of the $D C$ motor

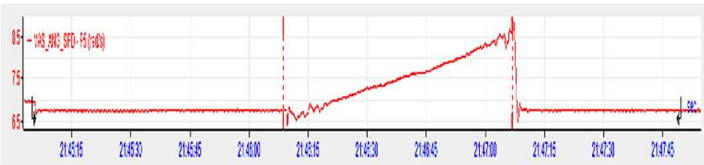

Fig. 20. Real speed of the DC Motor (Source: Liberty Galati)

In the real environment, at the F5 stand motor there is a constant increase of the speed, with 2 exceptions: at the beginning of rolling and at the end of rolling. These areas correspond to the time when the current was used in accordance with the variations introduced by the hydraulic screw positioning system Fig. 20.

\section{CONCLUSIONS}

The analysis of all the presented cases shows that in the simulation environment, where there are no mechanical or human operator variables, the current and speed controllers manage to adapt the motor parameters. In the real environment, the engines withstand harsh operating conditions from both the mechanical plant and the human operator. When the finishing train laminates the thin strip, the motor load is at maximum limit. The F5 stand that benefits from a hydraulic force production system can adjust the motor load during rolling. 


\section{REFERENCES}

Fulvio Siciliano Jr. (2012), Mathematical Modeling of the Hot Strip Rolling of $\mathrm{Nb}$ Microalloyed Steel. Metallurgical and Materials Transactions A 31(2):511-530, · DOI: 10.1007/s11661-0000287-8.

Hodgson P. D. (1993). Mathematical modelling of recrystallization processes during the hot rolling of steel, Ph.D. Thesis, University of Queensland, Australia. Gaetan Monari - Thickness, Width and Flatness control .

Marian Gaiceanu (2014). Tool of the Complete Optimal Control for Variable Speed Electrical Drives DOI: 10.5772/57521 In book: MATLAB Applications for the Practical Engineer (pp.339374) Chapter: Tool of the Complete Optimal Control for Variable Speed Electrical Drives Publisher: InTech.

Orowan, E. (1943). The Calculation of Roll Pressure in Hot and Cold Flat Rolling. Proceedings of the Institution of Mechanical Engineers, 150(1), $140-167$. doi:10.1243/pime_proc_1943_150_025 02.

Sims, R. B. (1954). The Calculation of Roll Force and Torque in Hot Rolling Mills. Proceedings of the Institution of Mechanical Engineers,, 168(1), 191-200. doi:10.1243/pime_proc_1954_168_023_02

William Roberts (1983). Hot Rolling of Steel, Marcel Dekker inc. New York.

https://www.libertyhousegroup.com 